ARASTIRMA

MAKALESİ

Yılmaz Mehmet ${ }^{1}$

Alper Başbu $\breve{g}^{2}$

Aşkı Ellibeş Kaya ${ }^{2}$

Mete Çağlar ${ }^{2}$

Atilla Özkara ${ }^{3}$

Mehmet Ali Sungur ${ }^{4}$

Safinaz Ataoğlu ${ }^{5}$

${ }^{1}$ Siirt Devlet Hastanesi Kadın Hastalıkları ve Doğum Kliniği

${ }^{2}$ Düzce Üniversitesi Tıp Fakültesi Kadın Hastalıkları ve Doğum Anabilim Dal1

${ }^{3}$ Giresun Kadın Doğum ve Çocuk Hastalıkları Hastanesi

${ }^{4}$ Düzce Üniversitesi T1p Fakültesi Biyoistatik Ve Tıbbi Bilişim Anabilim Dal1

${ }^{5}$ Düzce Üniversitesi Tıp Fakültesi

Fizik Tedavi ve Rehabilitasyon

Anabilim Dalı

Yazışma Adresi:

Alper Başbuğ

Düzce Üniversitesi Tıp Fakültesi Kadın

Hastalıklarl ve Doğum Anabilim Dalı

E-mail:dralper23@gmail.com

Gelis Tarihi: 18.01.2017

Kabul Tarihi: 15.03.2017

DOI: $10.18521 / \mathrm{ktd} .286409$

Konuralp Tıp Dergisi

e-ISSN1309-3878

konuralptipdergi@duzce.edu.tr

konuralptipdergisi@gmail.com

www.konuralptipdergi.duzce.edu.tr

\section{Osteoporoz Sıklığı ve Tarama Programı Başlangıç Yaşının Belirlenmesi: Düzce Üniversitesi Araştırma ve Uygulama Hastanesi Örneklemi}

\section{ÖZET}

Amaç: Yaptığımız bu çalışmada Düzce Üniversitesi Araştırma ve Uygulama Hastanesine başvuran kadınlarda osteoporoz sıklığını ve osteoporoz tarama başlangıç yaşını belirlemeyi amaçladık.

Materyal ve Metod: Düzce Üniversitesi Araştırma ve Uygulama Hastanesi fizik tedavi ve rehabilitasyon, kadın hastalıkları ve doğum ve ortopedi polikliniklerine 01.01.2015-31.12.2015 tarihleri arasında başvurarak DXA metoduyla femur boynu ve L1-L4 anterior vertebra KMY'ları ( Kemik mineral yoğunluğu) ölçülen 40 ile 70 yaş arasındaki 400 kadın çalışmaya dahil edildi. Majör osteoporotik kırık riskini belirlemek amacıyla FRAX çalışması anket soruları kadınlara sorularak bilgiler kaydedildi.

İstatistik: İstatistiksel analiz; gruplar arası Sürekli değişkenler Independent Samples T-test, kategorik değişkenler ise Pearson's chi-square test kullanılarak yapıldı. Sürekli değişkenler arasındaki ilişkiyi belirlemek için Pearson's korelasyon analizi kullanıldı.

Bulgular: Çalışmamıza katılan kadınlar arasında osteoporoz sıklığını $11.8 \%$ ve osteoporoz grubunun yaş ortalamasını 60.6 olarak bulduk.

Sonuç: Hastanemizin hizmet verdiği bölgede majör osteoporotik kırık risk faktörü bulunmayan kadınlarda osteoporoz taraması 60 yaşında başlamalıdır.

Anahtar kelimeler: Osteoporoz, kemik mineral yoğunluğu, DXA

\section{Determination Of The Age Of Onset To The Osteoporosis Screening Program And Frequency Of Osteoporosis: Düzce University Training And Research Hospital Sampling}

\section{ABSTRACT}

Aim: In our study, we aimed to determine the age of onset to the osteoporosis screening program and frequency of osteoporosis in the who admitted Düzce University Training and Research Hospital

Material and Methods: Between the dates 01.01.2015 and 31.12.2015, 400 women between the ages of 40 and 70, who applied to Düzce University Training and Research Hospital, Departments of Physical Therapy and Rehabilitation, Gynecology and Obstetrics, and Orthopedics, and had got their femoral neck and L1-L4 anterior vertebra BMD (Bone Mineral Density) measured with DXA method, were included in our research. With the FRAX trial questionnaire have conducted to determine major osteoporotic fracture risk, patient data were recorded via asking questions to patients.

Statistics: In the statistical analysis, Independent Samples T-test was evaluated for group comparison of continuous variables, Pearson's chi-square test was used for the analysis of relations between categorical variables, and Pearson's correlation analysis was used to review the relations between continuous variables.

Results: In our study, we determined the mean age of osteoporosis group as 60.6 while the frequency was demonstrated as $11.8 \%$.

Conclusion: For our region, we determined the age of onset for osteoporosis screening as 60 for women without a major osteoporotic fracture risk factor.

Key Words: Osteoporosis, bone mineral density, DXA 


\section{GİRIS}

Osteoporoz düşük kemik kütlesi ve kemik dokunun mikromimari yapısının bozulması sonucu kemik kırılganlığında artış ile karakterize sistemik bir iskelet hastalığıdır (1). Tüm dünyada insan yaşamının uzaması ile yaşlanan nüfusun artmasıyla, osteoporoz giderek önemli bir sağlık sorunu haline gelmiştir. Günümüzde 200 milyondan fazla insanın osteoporotik olduğu tahmin edilmektedir (2). Osteoporozun en önemli klinik sonucu frajilite kırıklarıdır (3). Osteoporotik kırıklar özellikle de kalça ve vertebra kırıkları mortalite ve morbidite açısından büyük önem arz etmektedir ve ağrı, dizabilite, fiziksel kısıtlılık ve bağımsızlığın azalması, psikososyal bozukluklar ve yaşam kalitesinde azalma gibi sonuçlar ile ilişkilidir (4) . Osteoporoz, kırıklar oluşmadan da tanısı konabilen, gerekli önlemlerle ve tedavilerle, kırıkların yaratacağı sağlık sorunlarının önlenebildiği bir hastalıktır bu nedenle hem osteoporotik kırık riski taşıyan popülasyonun hem de osteoporotik kırık riski taşımamasına rağmen belli yaşın üstündeki bireylerin taranması büyük önem arz etmektedir. Osteoporoz tanısında günümüzde altın standart olarak kabul edilen yöntem kemik mineral yoğunluğu (KMY)'nun dual X-ray absorbsiyometri (DXA) yöntemi ile ölçülmesidir (5). Buna göre genç erişkine göre kemik mineral yoğunluğunun (KMY) veya kemik mineral içeriğinin (KMI)-1 standart sapmanın (SD) altında olması normal, KMY'nun genç erişkine göre -1,0 SD ile -2,5 SD arasında olması osteopeni ve KMY'nun genç erişkine göre - 2,5 SD'dan fazla olması osteoporoz olarak tanımlanmaktadır (5). Osteoporozun önlenmesinde ve tedavisinde önemli bir yeri olan taramanın başlangıç yaşı ve sıklığı konusunda ise ülkeler ve dernekler arasında bir görüş birliği yoktur. Amerikan klinik endokrinoloklar derneği kadınlarda osteoporoz taramasını 65 yaş üstü kadınlarda 2 yılda bir önerirken, Japonya'da 40-70 yaş arasındaki kadınlar 5 yılda bir taramnaktadır (6-7). Ülkemizde ise Türkiye Endokrinoloji ve Metabolizma Derneği (TEMD) tarafindan 2016 yılında güncellenen 'Metabolik Kemik Hastalıkları Tanı ve Tedavi Kılavuzu'nda osteoporoz taramasına 65 yaşında başlanması ve 2 yılda bir yapılması önerimektedir (8).

Biz de bu çalışmayı Düzce Üniversitesi Eğitim ve Araştırma hastanesi Fizik Tedavi ve Rehabilitasyon , Kadın Hastalıkları ve Doğum ve Ortopedi polikliniklerine başvuran kadınlar arasında osteoporoz sıklığını ve osteoporoz taraması başlangıç yaşını belirlemek amacıyla yaptık. Osteoporoz tarama yaşını belirlemeye çalışmamızın temel nedeni TEMD tarafından önerilen 65 yaş sınırının bölgemize uygun olup olmadığını anlamak ve taramaya uygun yaşta başlayarak osteoporoz açısından risk altındaki populasyonun maliyetetkin bir tarama programına dahil edilerek osteoporoz tanısı alan kadınların uygun bir şekilde tedavisine başlayıp kalça ve bel fraktürlerini önleyerek bunları tedavi maliyetlerini azaltmaya yardımcı olmaktı.

MATERYAL VE METOD

Retrospektif nitelikteki bu çalışma Düzce
Üniversitesi Tıp Fakültesi Etik Kurul Komitesinin onayı alınarak yapıldı (2015/170). Tüm prosedürler Helsinki Deklerasyonu ile uyumlu olarak yapıldı. Çalışmaya 01.01.2015-31.12.2015 tarihleri arasında Düzce Üniversitesi Eğitim ve Araştırma hastanesi Fizik Tedavi ve Rehabilitasyon, Kadın Hastalıkları ve Doğum ve Ortopedi polikliniklerine başvurup DXA yöntemiyle femur boynu ve L1-L4 anterior vertebra KMD ölçümü yaptıran 40-70 yaş arası 600 kayıtlı kadın hasta dahil edildi.600 $\mathrm{Bu}$ hastaların 400'nün iletișim bilgilerine hastane kayıt sistemi kullanılarak ulaşıldı ve hastalar telefon ile tekrar arand1 .Major osteoporoz kırık risk faktörlerini belirlemek için yapılan FRAX çalıșması anket formu ile hastalara soru sorularak bilgileri kaydedildi. Çalışmaya dahil olan 400 kadının vücut kitle indeksi(VKI )hesaplandi. Osteoporoz ve majör osteoporotik kırık risk faktörlerinden yaş, erken menopoz öyküsü , sigara kullanımı, ebeveynlerde osteoporotik kırık öyküsü, romatoid artrit, glikokortiokid kulanma öyküsü (en az üç ay) , sekonder osteoporoz öyküsü, hormon replesman tedavisi alıp almadığ sorgulandı. Tüm vakaların kemik mineral yoğunluğu GE/LUNAR DPX PRO markalı KMY cihazı ile ölçüldü.

\section{İstatistik Analiz}

Sürekli değişkenler ortalama ve standart sapma, kategorik değişkenler frekans ve yüzde şeklinde özetlenmiştir. Sürekli değişkenler bakımından grup karşılaştırmalarında Independent Samples $t$ test kullanılmıştır. Kategorik değişkenler arası ilişkilerin incelenmesinde ise Pearson ki-kare testi, sürekli değişkenler arasındaki ilişkilerin incelenmesinde ise Pearson korelasyon analizi yapılmıştır. İstatistik analizler SPSS v.22 paket programı ile yapılmış ve anlamlılık düzeyi 0.05 olarak dikkate alınmıştır.

\section{BULGULAR}

Çalışmaya katılan kadınların yaş ortalaması

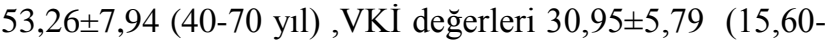
$55,24)$ olarak saptand.

Tablo 1. Çalışmaya dahil edilen hastaların yaş,boy, ağırlık ve VKI 'nin ortalaması

\begin{tabular}{|l|c|c|c|}
\hline & $\mathrm{n}$ & Mean & Std. Deviation \\
\hline YAŞ(yıl) & 400 & 53,26 & 7,94 \\
AĞIRLIK(kg) & 400 & 76,48 & 14,43 \\
BOY (m) & 400 & 1,57 & 0,06 \\
VKİ & 400 & 30,95 & 5,79 \\
\hline
\end{tabular}

Çalışmamıza dahil edilen 400 kadının majör bir osteoporotik kırık geçirme olasığı açısından klinik risk faktörleri değerlendirildiğinde ,hastaların kırık öyküsü olanlar \%3.5(14), ailede kırık öyküsü olanlar \%4(16) ,sigara içme öyküsü olanar \%13,25(53), steroid kulanma öyküsü olanlar \%8(32), sekonder osteoporoz olanlar \%3.25(13), RA hastalığı olanlar \%1.50(6) ,alkol kulanım öyküsü olanlar \%0.25(1) ,HRT öyküsü olanlar \%4.75(19) ve erken menopoz öyküsü olanlar \%4.50(18) olarak saptand 1 
Tablo 2:Çalışmadaki hastaların majör osteoporotik kırık risk faktörleri

\begin{tabular}{|c|c|c|c|}
\hline & VAR(\%) & YOK(\%) & TOPLAM(\%) \\
\hline KIRIK ÖYKÜSÜ & $14(3.50)$ & 386(96.50) & $400(100)$ \\
\hline AILE KIRIK ÖYKÜSÜ & $16(4.00)$ & 384(96.00) & $400(100)$ \\
\hline SİGARA İÇME ÖYKÜSÜ & $53(13.25)$ & $347(86.75)$ & $400(100)$ \\
\hline $\begin{array}{c}\text { STEROİD KULLANMA } \\
\text { ÖYKÜSÜ }\end{array}$ & $32(8.00)$ & $368(92.00)$ & $400(100)$ \\
\hline RA HASTALIĞI VARLIĞI & $6(1.50)$ & 394(98.50) & $400(100)$ \\
\hline $\begin{array}{c}\text { SEKONDER } \\
\text { OSTEOPOROZ VARLIĞI }\end{array}$ & 13(3.25) & $387(96.75)$ & $400(100)$ \\
\hline $\begin{array}{c}\text { ALKOL.KULLANIM } \\
\text { ÖYKÜSÜ }\end{array}$ & $1(\% 0.25)$ & 399(\%99.75) & $400(\% 100)$ \\
\hline HRT. ÖYKÜSÜ & $19(4.75)$ & 381(95.25) & $400(100)$ \\
\hline $\begin{array}{c}\text { ERKEN MENOPOZ } \\
\text { ÖYKÜSÜ }\end{array}$ & $18(4.50)$ & 382(95.50) & $400(100)$ \\
\hline
\end{tabular}

Femur boynu KMD'sine göre, hastaların 240'1 $(\% 60,00)$ normalken, 151'i $(\% 37,75)$ osteopenik ve 9'u $(\% 2,25)$ osteoporotikdi. L1-L4 anterior vertebra KMD'sine göre, hastaların 248'i $(\% 62,00)$ normalken,
126 's1 $(\% 31,50) \quad$ osteopenik ve 26 's1 $(\% 6,50)$ osteoporotikdi. Femur boynu veya L1-L4 anterior vertebra KMD'sine göre hastaların 160 ' $1(\% 40,00)$ normalken, 208'i(\%52,00) osteopenik ve 32'si(\%8,00) osteoporotikdi.

Tablo 3: Çalışmaya dahil olan hastaların Osteoporoz ve Osteopeni oranı

\begin{tabular}{|c|c|c|c|c|}
\hline & $\begin{array}{c}\text { Normal(\%) } \\
\text { (t skoru>-1) }\end{array}$ & $\begin{array}{c}\text { Osteopeni(\%) } \\
\text { (t skoru -1 ile - } \\
\text { 2.5arasinda) }\end{array}$ & $\begin{array}{c}\text { Osteoporoz(\%) } \\
\text { (t skoru<-2.5) }\end{array}$ & Toplam(\%) \\
\hline $\begin{array}{c}\text { Femur boynu } \\
\text { KMD }\end{array}$ & $240(60.00)$ & $151(37.75)$ & $9(2.25)$ & $400(100)$ \\
\hline $\begin{array}{c}\text { L1-L4 anterior } \\
\text { vertebra KMD }\end{array}$ & $248(62.00)$ & $126(31.50)$ & $26(6.50)$ & $400(100)$ \\
\hline $\begin{array}{c}\text { Femur boynu veya } \\
\text { L1-L4 anterior } \\
\text { vertebra KMD'ne } \\
\text { göre }\end{array}$ & $160(40.00)$ & $208(52.00)$ & $32(8.00)$ & $400(100)$ \\
\hline
\end{tabular}

$\mathrm{Bu}$ çalışmada 40-49 yaş grubunda osteoporoz tanısı için Z skoru; 50-59,60-70 yaş gruplarında ise $T$ skoru kulanıldı. Osteoporoz prevalansı yaş gruplarına göre farklılık göstermektedir. 40-49 yaşgrubunda \%1,4, 50-59 yaş grubunda $\% 8,0$ ve $60-70$ yaş grubunda \%17,5 olup, 50-59 ve 60-70 yaş gruplarının her ikisinde de 40-49 yaşa göre anlamlı şekilde yüksek olduğu saptandı $(\mathrm{p}<0.001)$.

Tablo 4: Çalışmaya dahil olan hastaların yaş gruplarına göre osteoporoz prevalansı

\begin{tabular}{|c|c|c|c|c|}
\hline & & osteoporoz & normal & Toplam \\
\hline \multirow{3}{*}{ yas } & $40-49$ & $\begin{array}{c}2 \\
1.4 \%\end{array}$ & $\begin{array}{c}145 \\
98.6 \%\end{array}$ & $\begin{array}{c}147 \\
100.0 \%\end{array}$ \\
\hline & 50-59 & $\begin{array}{c}12 \\
8.0 \%\end{array}$ & $\begin{array}{c}138 \\
92.0 \%\end{array}$ & $\begin{array}{c}150 \\
100.0 \%\end{array}$ \\
\hline & $60-70$ & $\begin{array}{c}18 \\
17.5 \%\end{array}$ & $\begin{array}{c}85 \\
82.5 \% \\
\end{array}$ & $\begin{array}{c}103 \\
100.0 \%\end{array}$ \\
\hline \multicolumn{2}{|c|}{ Toplam } & $\begin{array}{c}32 \\
8.0 \%\end{array}$ & $\begin{array}{c}368 \\
92.0 \%\end{array}$ & $\begin{array}{c}400 \\
100.0 \%\end{array}$ \\
\hline
\end{tabular}

Yaş bakımından osteporoz grubunda olanlarla olmayanlar arasında istatiksel anlamda farklılı vardı $(p<0,001)$. Osteoporoz grubunda yaş ortalaması daha yüksekiken(60,66), olmayanların ise daha düşük olarak saptandi(52,62). 


\section{TARTIŞMA}

Sunduğumuz çalışmada hastanemiz fizik tedavi ve rehabilitasyon, kadın hastalıkları ve doğum ve ortopedi polikliniklerine başvuran kadınlar arasında tüm yaş grupları içerisinde osteoporoz sıklığını \%8.0, osteopeni sıkılı̆̆ını ise \%52.0 olarak, osteoporotik hastaların yaşlarının aritmetik ortalamasını ise 60.66 olarak belirledik.

Osteoporozu toplumsal açıdan önemli kılan oluşan kırıklar nedeniyle tedavi maliyetinin ve ölüm oranının artması ile bireylerin ekonomik ve iş gücündeki kayıpların büyüklüğüdür (9). Bu nedenle osteoporozun erken tanısı ve tedavisi için tarama programlarının uygulanması önem arz etmektedir. TEMD tarafindan KMY ölçüm ve değerlendirmesinde tanı için DXA yönteminin kullanılmasını, postmenopozal kadınlar için $\mathrm{T}$ skorunun değerlendirilmesi gerektiğini ve risk faktörü taşımayan kadınların ise 1-2 yıl aralıklarla taranması gerektiğini belirmiştir (10-13). Bizde yaptığımız çalışmada TEMD önerileri doğrultusunda tarama için DXA yöntemini kullandık ve postemenopozal osteoporoz tanısını T skoru sonucuna göre koyduk.

ACOG 2012 osteoporoz bülteninde; 65 yaş üstü her hastaya KMD yapılmasını önermektedir, ayrıca artmış bir risk faktörü yoksa ve T skoru -1.5'un üstünde ise , KMD'si normalse 15 yılda bir tarama önermektedir. Tskoru -1.5 ile -1.99 arasinda ise 5 yılda bir, -2 ile 2.49 arasında ise yılık tarama yapılmasını önermektedir (13).
Scientific Advisory Council of Osteoporosis Canada tarafindan 2010 yılında yayınlanan Osteoporoz tanı ve yönetimi kılavuzunda 65 yaş üstü tüm kadınlarda KMD ölçümünü önermektedir (14).

Çalışmamızda ortalama osteoporoz başlangıç yaşının bu derneklerce belirtilen tarama başlangıç yaşına göre daha düşük olduğunu tespit ettik. $\mathrm{Bu}$ nedenle osteoporoz taramasına bölgemizde daha erken başlanabileceğini kanaatindeyiz.

Türkiye'de 50 yaş ve üzerindeki kadnların \%50'sinde osteopeni ve \%12.9'unda osteoporoz saptanmıştır. (15-16). Bizde yaptığımız bu çalışmamızda 50 yaş ve üzeri kadınlarda $\% 52(n=208)$ oranında osteopeni ve $\% 11.8(n=30)$ oranında osteoporoz, saptadık. Bulduğumuz bu oranlar literatürdeki diğer çalışmalar ile uyumluydu(17).

\section{SONUÇ}

Osteoporoz yaşam süresi uzadıkça giderek daha büyük ve daha önemli bir halk sağlığ 1 sorunu haline gelmektedir. Pek çok hastalıkta olduğu gibi osteoporozda da korunma, erken tanı önemlidir. Bu nedenle özellikle postmenopozal dönemdeki kadınların KMY'luklarının ölçülerek osteopeni ve osteoporoz vakalarının erken tespiti ve kırık riskinin değerlendirilerek gerekli tedavinin başlanması önem kazanmaktadır. Bu taramalar yapılırken bölgesel farlılıklar da göz ardı edilmemelidir.

\section{KAYNAKLAR}

1- Cosman F, de Beur S J, LeBoff M S, Lewiecki EM, Tanner B, Randall S et al. Clinician's Guide to Prevention and Treatment of Osteoporosis. Osteoporos Int 2014; 25 (10): 2359 - 81.

2- Cooper C, Campion G, Melton LJ 3rd. Hip fractures in the elderly: a world-wide projection. Osteoporosis Int. 1992 Nov; 2(6): 285-9.

3- Papaioannou P, MorinS, Cheung AM, Atkinson S, Brown JP, Feldman S et al. for the Scientific Advisory Council of Osteoporosis Canada. Clinical Practice Guidelines for the Diagnosis and Management of Osteoporosis in Canada. CMAJ 2010 (17); 182

4- Eryavuz M. Osteoporozun tanımı, sınıflandırması ve epidemiyolojik çalışmalar. Gökçe YK (Ed). Fiziksel Tıp ve Rehabilitasyon 2002; 1(2) : 1-10

5- WHO Scientific Group on the Prevention and Management of Osteoporosis. Prevention and management of osteoporosis: report of a WHO scientific group. Internet Communication. 2007

6- Nelson B. Watts, John P. Bilezikian, Pauline M. Camacho, Susan L. Greenspan, Steven T. Harris, Stephen F. Hodgson et al. American association of clinical endocrinologists medical guidelines for clinical practice for the diagnosis and treatment of postmenopausal osteoporosis. Endocr Pract 2010; 16(3): 1-37.

7- Hajime Orimo, Toshitaka Nakamura, Takayuki Hosoi, Masayuki Iki, Kazuhiro Uenishi, Naoto Endo. Japanese 2011 guidelines for prevention and treatment of osteoporosis-executive summary. Arch Osteoporos 2012 Dec; 7(1-2): 3-20.

8- Türkiye Endokrinoloji ve Metabolizma Derneği. Osteoporoz ve Metabolik Kemik Hastalıkları Tanı ve Tedavi Kılavuzu. 11. Bask1. Ankara, 2016; 11-14.

9- NIH Consensus Development Panel on Osteoporosis Prevention, Diagnosis, and Therapy. JAMA 2001; 285 : 785-95.

10- AACE Medical Guidelines for clinical practice fort he diagnosis and treatment of postmenopausal osteoporosis. Endocrine Practice 2010; 16(3): 1-37.

11- National Osteoporosis Foundation. Clinician’s Guide to Prevention and Treatment of Osteoporosis. Washington, DC: National Osteoporosis Foundation; 2010.

12- Schousboe JT, Vokes T, Broy SB, Ferrar L, McKiernan F, Roux C, Binkley N. Vertebral fracture assessment: the 2007 ISCD official positions. J Clin Densitom 2008; 11 (1): 92-108

13- ACOG Practice Bulletin N. 129. Osteoporosis. Committee on Practice Bulletins-Gynecology, The American College of Obstetricians and Gynecologists. Obstet Gynecol 2012 Sep;120 (3): 718-34.

14- 2010 Clinical Practice Guidelines for the Diagnosis and Management of Osteoporosis: To revise and expand the 1996 Osteoporosis Society of Canada clinical practice guidelines for the management of osteoporosis. CMAJ 2002; 167 (10): $1-34$ 
15- The Middle East \& Africa Regional Audit, Epidemiology, costs \& burden of osteoporosis in 2011. International Osteoporosis Foundation “IOF” 2011 basımı.. Ş.Tüzün,Ü. Akarırmak. Türkiye verileri: 59-62.

16- Arasıl T, Osteoporoz Epidemiyolojisi ve Türkiye Verileri. Türkiye Klinikleri JPM\& R. Special Topics 2009; 2(1): 1-8.

17- Lokeer AC, Orwoll ES, Johnson CC. Prevalence of low femoral density in older US adults from NHANCES III. J Bone Mineer Res 1997;12 (11): 1761-1768. 